\title{
WISE game: wireless interactive software educational game
}

\author{
Muel Fred L. Ruiz ${ }^{1}$, Rica I. Esclada ${ }^{2}$, Jannica H. Balderama ${ }^{3}$, Anzel Anne I. Aguirre ${ }^{4}$, \\ Ma. Nancy I. Cutin ${ }^{5}$, Raymund M. Lozada ${ }^{6}$ \\ ${ }^{1,6}$ Electrical and Allied Department, Technological University of the Philippines Taguig, Philippines \\ 2,3,4,5Technological University of the Philippines Taguig, Philippines
}

\begin{tabular}{l} 
Article Info \\
\hline Article history: \\
Received Jan 14, \\
Revised Jun 22, \\
Accepted Aug 4, \\
\hline Keywords: \\
Gamification \\
Microcontroller \\
Raspberry Pi 3 \\
Smartphone \\
WLAN
\end{tabular}

WLAN

\begin{abstract}
This study presents the development of a wireless, interactive, educational (WISE) game that incorporates the use of smartphones for reviewing lessons that might suit the standards of the Philippine government's education department. It is easier today to engage students using digital platforms for education using interactive digital games. In this study, the users can play the game by connecting the smartphones to the prototype through wireless local area network. It consists of two types of cards: power cards which contribute excitement to the game, and question cards which contain questions to be answered by the players. The prototype is an integration of the following components: Raspberry Pi 3B, RFID reader and cards, and speakers. A graphical user interface where the players interact with the game was created using scripting languages, such as PHP, and JavaScript. The project was evaluated by different grade school students of Metro Manila, Philippines. The results of users' evaluation show that the prototype is accessible and effective for use based on functionality and that the project can also serve as a tool for lesson reviews. Future development of WISE game includes its integration and compatibility to different operating systems with larger databases and accessibility.
\end{abstract}

This is an open access article under the CC BY-SA license.

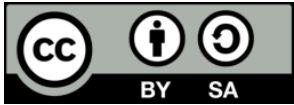

\section{Corresponding Author:}

Muel Fred L. Ruiz

Electrical and Allied Department

Technological University of the Philippines

Km. 14 East Service Road, Western Bicutan Taguig City, Philippines

Email: muelfredruiz@gmail.com

\section{INTRODUCTION}

Educational games have changed through the advancement of technology. With the rapid pace of technology, educational tools and methodologies are needed to be developed to reach new generations of students. Students spend twice as much time on gadgets as they do in academics [1]-[3]. Students from this generation are known to quickly adapt and accept technology, rather than sticking to the old traditional ways of learning, which are hard to deal with for them [4], [5]. With that, it is easy for the students to utilize their time in learning lessons by using the technologies they grow up with, especially smartphones. To engage and educate this generation, adaptation of technology through games prepares them to a technology driven, interconnected and competitive world of the 21st century. The challenges on this generation inflicted by rapidly changing technology are significant, as the knowledge obtained by means of classical education are no longer seen as sufficient preparation for their future [6]-[8]. By this reason, games requiring a system that incorporates technology have become evident as a new tool for learning. These games are designed to inform humans about a definite subject to equip them with skills [9]. These games upskill goals, rules, adaption, problem solving, and interaction, while it delivers basic needs of learning by providing enjoyment, passionate involvement, structure, motivation, ego gratification, adrenaline, 
creativity, social interaction, and emotion [10]. To help maximize the learning capabilities and skills of these students using technology that is evolving today, the proponents prompted to conduct this study.

Demands on redesigning the educational system for more effective preparation of students for a much more technology driven, interconnected, and competitive "flat world" are being pointed-out by parents, educators, politicians, and others across the globe. Sustaining the same old approach to students as the world continues to advance will not serve them excellently since old-fashioned ways of teachings are outdated to the present technologies [11], [12]. Students nowadays are growing up with gadgets such as mobile phones, tablets, laptops, and computers, and these technologies have become an integral part of their daily interactions [13]-[16]. Children between the ages of 8 and 18 spend more than 7 hours, on average, per day with digital media [17]-[19]. When the use of more than one digital device at a time is considered, they spend more than 10 hours a day with digital technologies [1]. More than $50 \%$ of tweens (ages 8 to 12) have their own tablet, and more than $60 \%$ of teens have their own smartphones. Mobile devices account for $41 \%$ of all screen time for tweens and $46 \%$ for teens [18]. Thus, spending the time reading books is lessening as the technology rises.

One of the studies, Kahoot! [20]-[24], have warranted strong results from using technology in studying and made learning more fun, engaging, interactive and social. It is reliable for the teachers to use as an educational tool to create multiple choice quizzes, which can be answered on mobile devices, laptops, and desktops. Further, research shows that serious games can be a powerful instructional tool and can give motivation and interest to students in their subjects, which supplements their learning [25]-[27].

The primary purpose of the study is to create an electronic-tabletop game that composes tangible power cards to twist the game and electronic question cards to be answered by the users and to test its feasibility to grade school students. Its access is through their own smartphone's web browsers, connected through a wireless local area network (WLAN) of the game. This will be used as a purely educational and interactive game for grade school students.

\section{RESEARCH METHOD}

\subsection{Tests and evaluation}

The prototype will be tested and evaluated by 130 different users from grade 5 to grade 8 students at different schools in Metro Manila, Philippines. After each test, the users will rate each category from the scale of 1 to 4, with 4 as the highest score equivalent to "Excellent". This will determine the ratings of the prototype in terms of aesthetics, functionality, feasibility, reliability, and security. The evaluation form used is shown in Figure 1. The computed mean scale presented in Table 1 will be used to interpret the result of evaluation for each category.

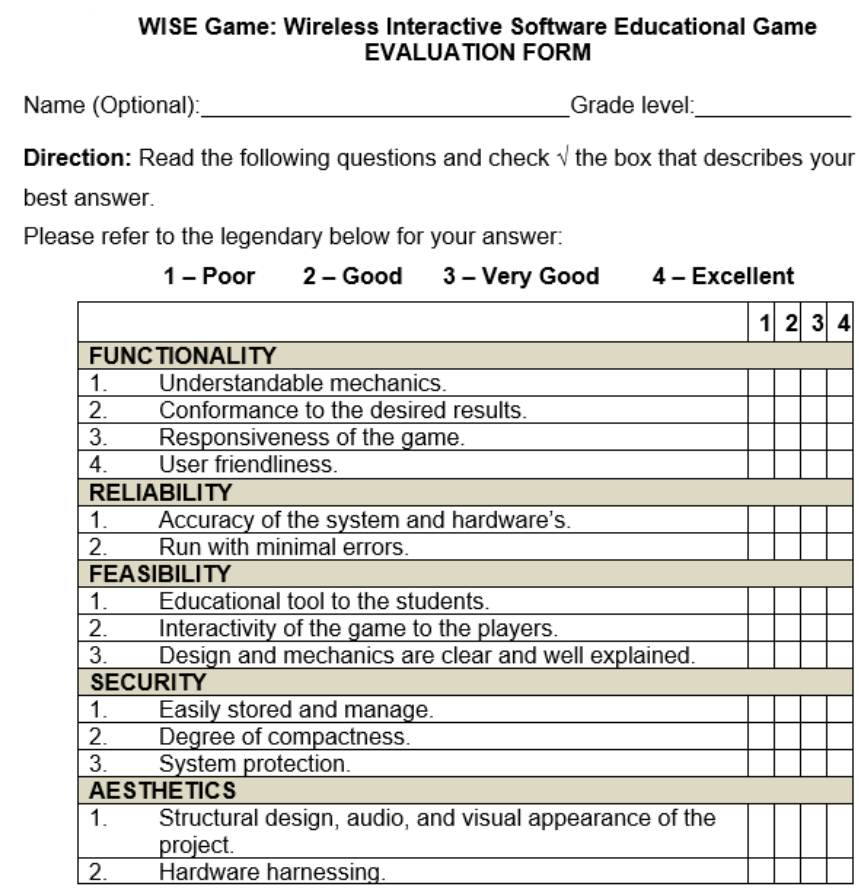

Figure 1. Evaluation form 
Table 1. Computed mean scale

\begin{tabular}{cc}
\hline Scale & Equivalent \\
\hline $3.26-4.00$ & Outstanding \\
$2.51-3.25$ & Good \\
$1.76-2.50$ & Bad \\
$1.00-1.75$ & Very Bad \\
\hline
\end{tabular}

\subsection{Game mechanics}

The goal of each player is to score the highest at the end of ten (10) rounds. But in order to, players must earn game points, and sometimes, prevent other players from earning them. To earn game points, players must answer every given question correctly. The game is played by 2-4 players. The game requires each player a mobile phone, a pen, and piece/s of paper.

The game consists of 2 types of cards: Question cards and power cards. Question cards contain questions with multiple choices that will be answered by the players to gain scores. A sample question card is shown in Figure 2(a) (Note: Question cards are not actually playing cards. These "cards" are digital information displayed on the smartphones of each player). Using Power cards create different effects on the game, according to their specification and use. "Power cards" are RFID cards. To use these cards, the player in turn will tap the RFID card to the reader. Sample power cards is shown in Figure 2(b).

At the start of the game, each player will draw a maximum number of 5 power cards from the deck. There are 10 rounds in a game. Each round, the players will answer one question in different subjects based on their grade level they chose. They can use the power cards after the first question. A round indicator will prompt on the screen of each player at the beginning of each round, as shown in Figure 3.

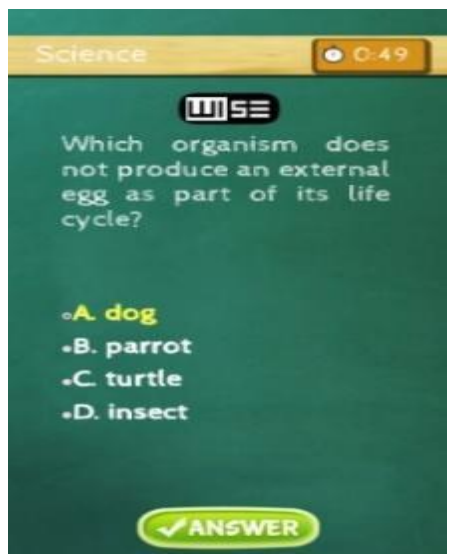

(a)
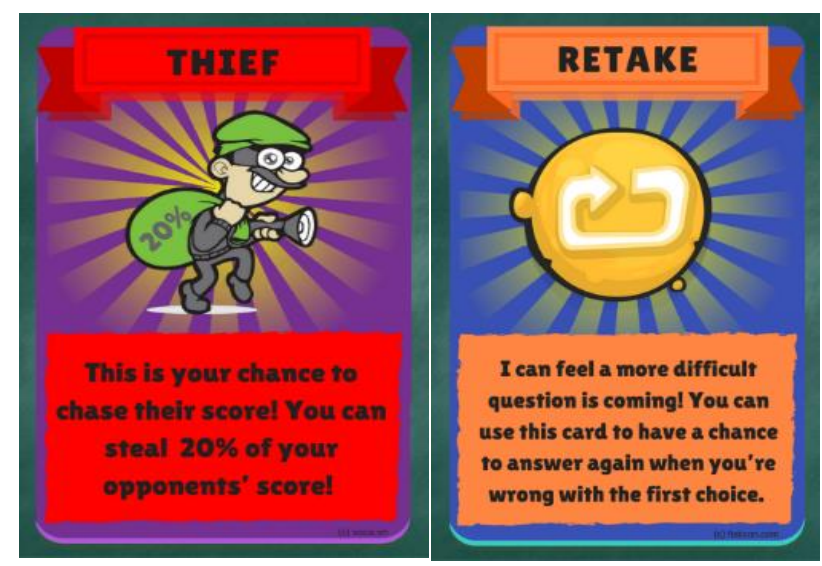

(b)

Figure 2. (a) sample of question card, (b) sample power cards

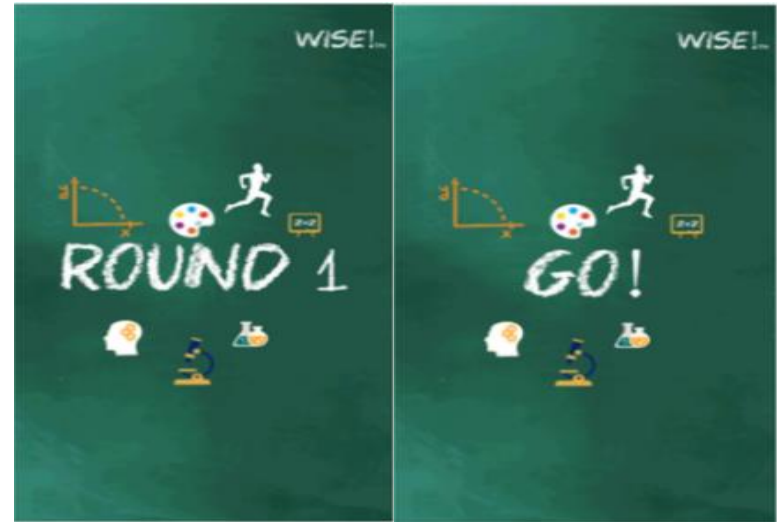

Figure 3. Round indicator shown at the start of every round 
The player during his/her turn:

1. Should answer the question card given by the system. All players are given 1 minute and 45 seconds to answer each question.

2. Every after the question, players are chosen randomly who will be the first one to use a power card. Players are required to use one power card only. Touch moves are highly implemented when using power cards.

3. Draw one power card (RFID card from the deck).

4. He/she will receive another question from the system and use a power card until they reach the last round. A message will prompt the player's screen when it is time to use a power card, as shown in Figure 4.

Players can get a score after answering question cards from each round. Each round, the player who first answered correctly will get the highest point of 3 . The 2 nd one will get a point of 2 . For the third and fourth will get a point of 1 . If the player got the wrong answer or ran out of time automatically, he/she will get 0 .

Each player has 6 Professionals, namely: Scientist, Mathematician, Interpreter, Historian, Artist, and Athlete, in which corresponds to 6 categories/subjects where random questions came from. Each professional can be leveled from 1-3. The level of each professional will be a multiplier of game points earned in every correct answer to questions in their category. (e.g., a level 2 Mathematician will give x2 multiplier to game points earned from questions in the mathematics subject; a level 3 scientist will give $\mathrm{x} 3$ to game points to questions in science subject). To level-up the professionals, players use "Level-up" from the power cards, they can choose up to three specialists depending on what kind of "Level up" card they got and press the button for the selected specialist. "Level up" power cards are shown in Figure 5. The player who has the highest points at the end of 10 rounds wins the game. The program will prompt the overall ranking of each player, as shown in Figure 6.

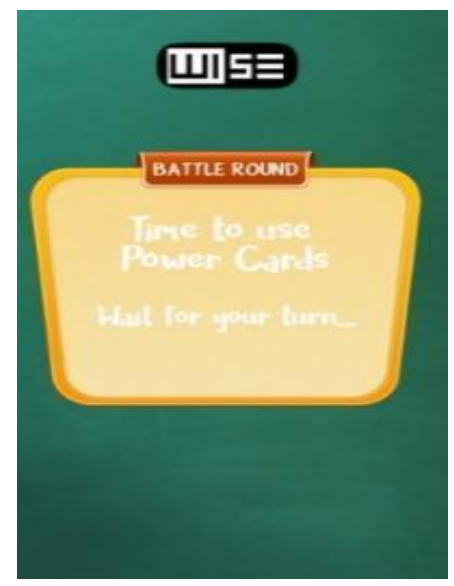

(a)

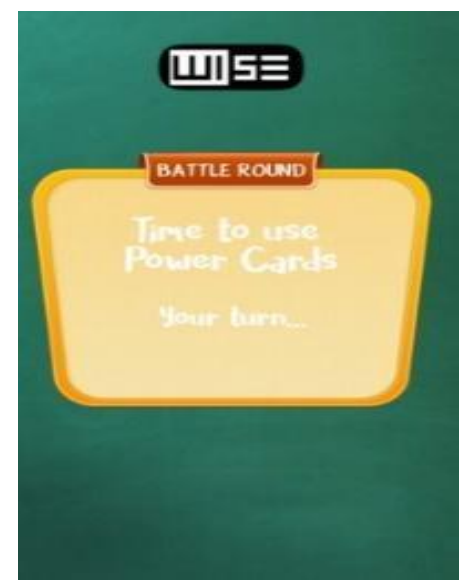

(b)

Figure 4. Messages received by players: (a) before, (b) during their turn to use power cards

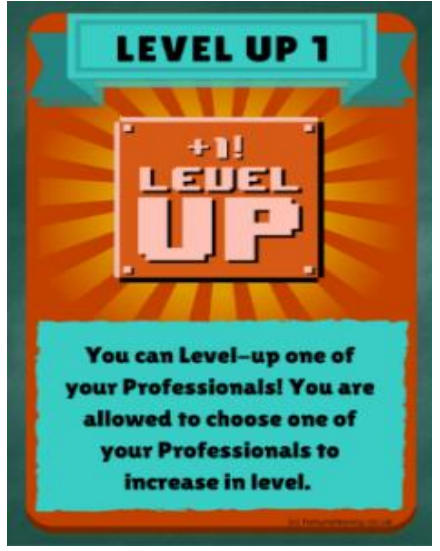

(a)

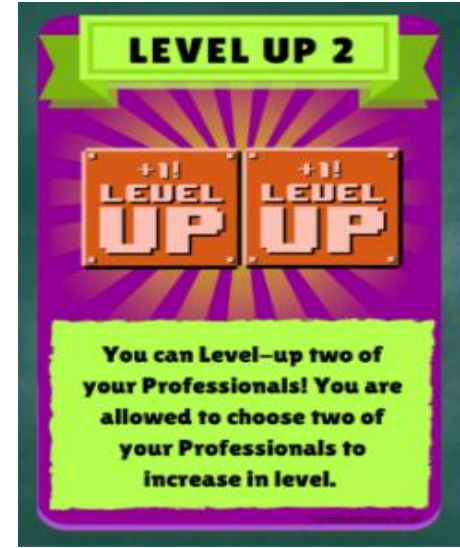

(b)

Figure 5. "Level Up" power cards 

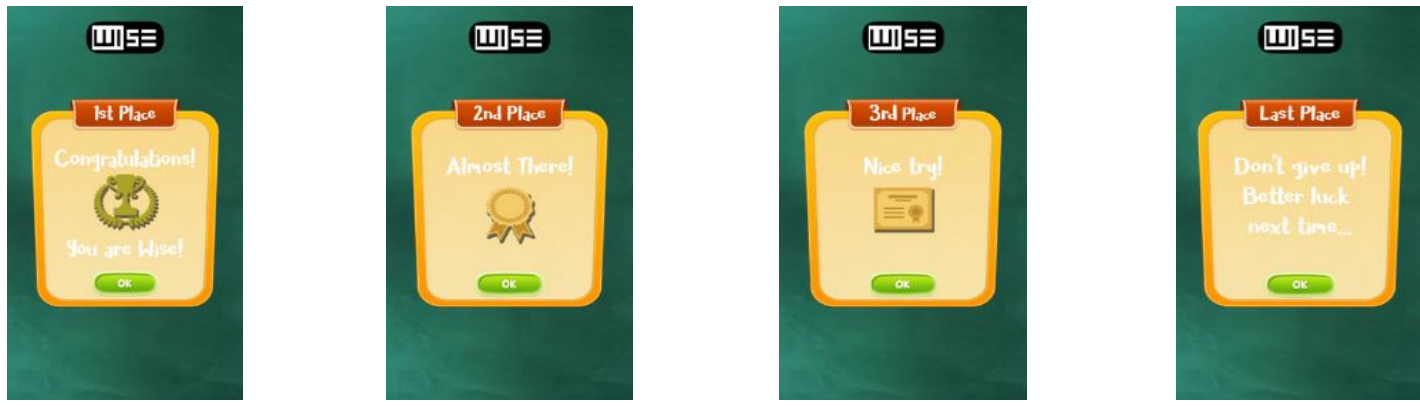

Figure 6. Final rankings shown on each player's screens after the $10^{\text {th }}$ round

\subsection{Prototype design}

The system is composed of RFID card reader, input buttons circuit module, scoring display module, and speakers, which are all connected to the input and output ports of the Raspberry Pi. The Raspberry Pi serves as the central processing unit of the game. It is used as the game server that connects the smartphones to the game that is available through WLAN connection. The RFID card reader is connected to the Raspberry $\mathrm{Pi}$. It is used to read and execute "Power cards". Raspberry Pi is also responsible for producing audio output for sound effects and background music. These audio outputs are mp3 files stored in the external hard drive. The project block diagram is shown in Figure 7.

To make the unit playable outdoors, Lithium-ion batteries are installed to provide electricity to the whole system for a time duration even with the absence of an external power source. To regulate the charging and discharging of these batteries, voltage/current regulator circuits are provided. The power supply system is shown in Figure 8. The structural design of WISE is based on a maximum of 4 players, to accommodate the hardware inside the electronics board the proponent set the width to 4 inches, assuming the size of the microprocessor and the I/O peripherals. The width is 20 inches by 20 inches, to accommodate and to have a right amount of place per player. Detailed presentation of the structural design is shown in Figure 9.

The software loaded in the Raspberry Pi microprocessor performs the sequence of the game. Right after the user switches the power-on, the system begins to boot-up. Then, the system will automatically start the web server Apache [28], MySQL [29], hostapd [30], and dnsmasq. And the game will start after all the smartphones of the players are connected to the server and the start button in the graphical user interface is pressed. Detailed presentation of the software design is shown in Figure 10.

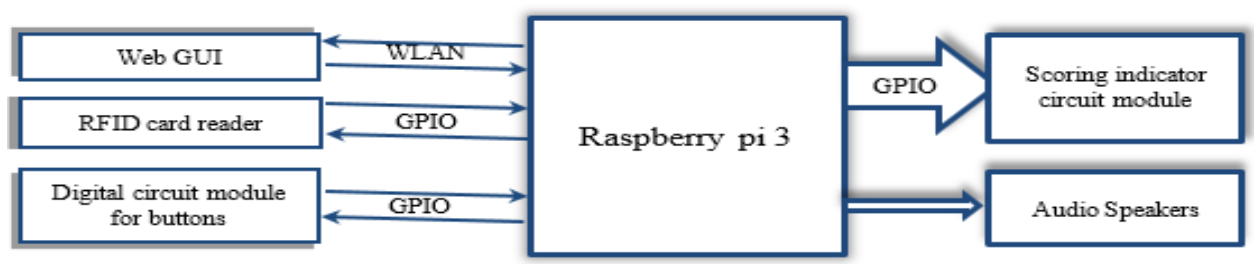

Figure 7. Project block diagram

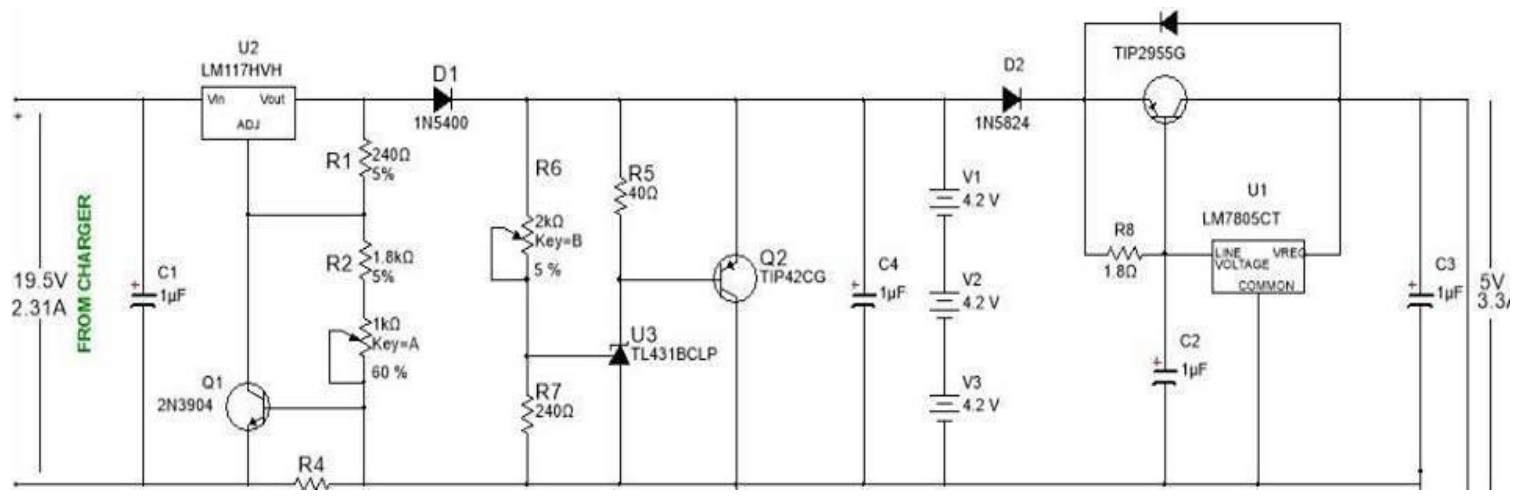

Figure 8. Power supply system used for the prototype 


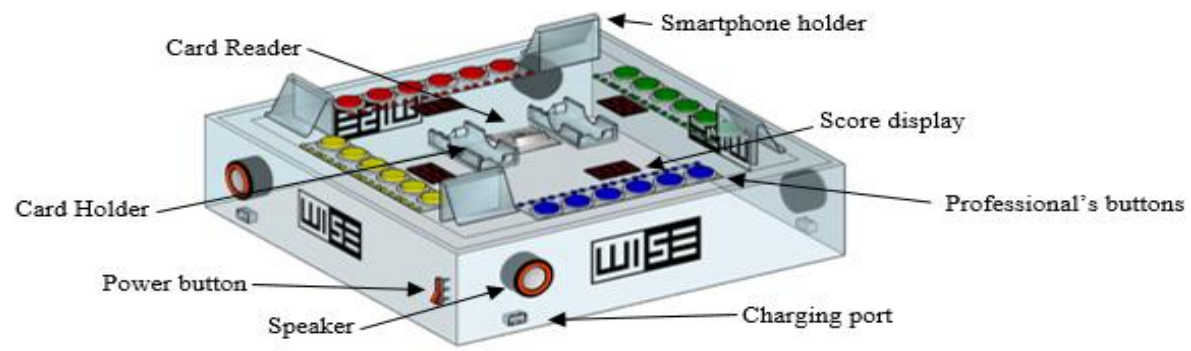

Figure 9. Structural design
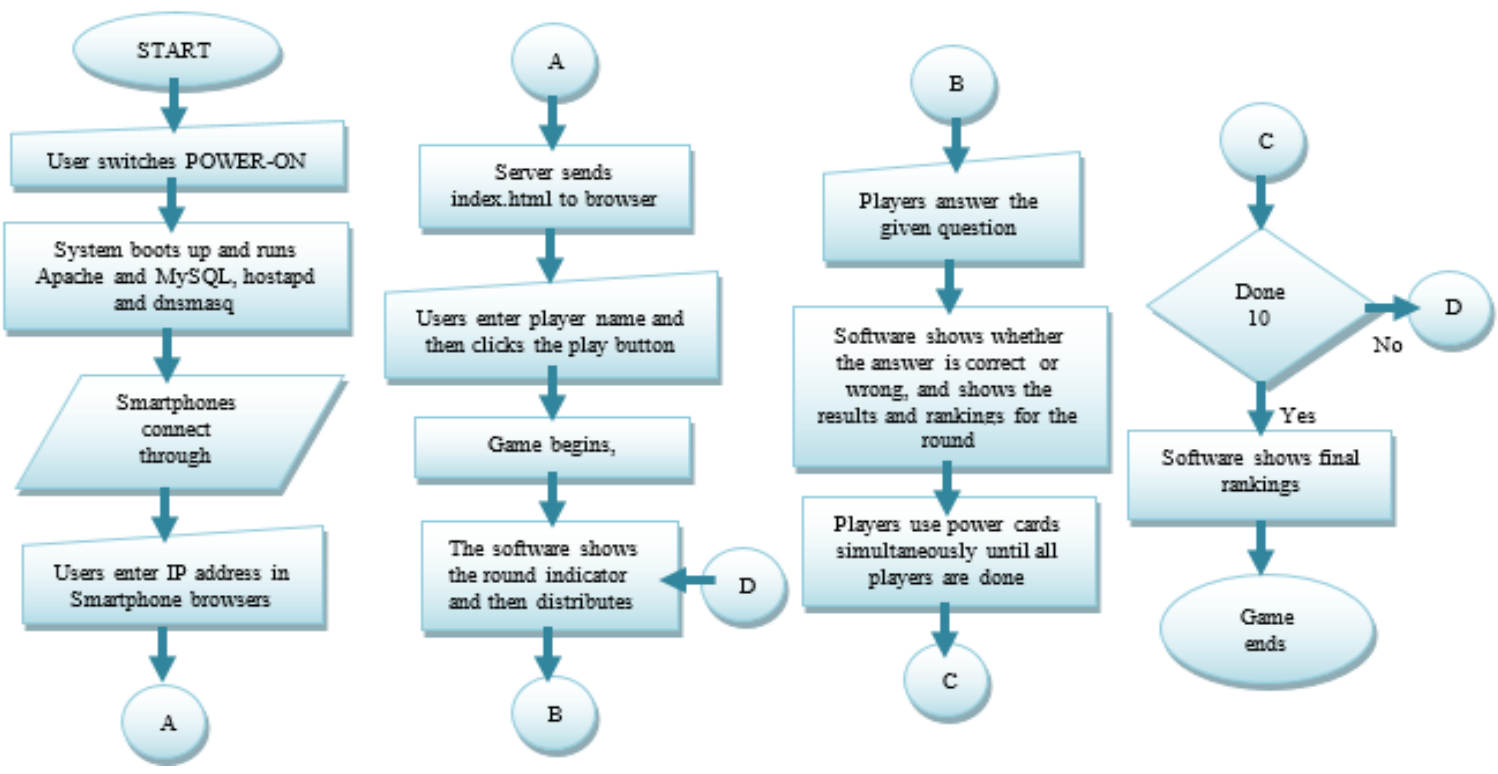

Figure 10. Software design

\section{RESULTS AND DISCUSSION}

Respondents were asked to evaluate the performance of the WISE Game. The game was rated based on its functionality and ease of use with regards to user interface, mechanics of the game, interactions of devices, security, aesthetics, and others. The results of the performance evaluation are presented in Table 2.

Table 2. Project evaluation results

\begin{tabular}{|c|c|c|c|c|c|}
\hline \multirow[t]{2}{*}{ Questions } & \multicolumn{4}{|c|}{ Number of respondents (out of 130) } & \multirow[t]{2}{*}{ Mean } \\
\hline & Poor & Good & Very good & Excellent & \\
\hline \multicolumn{6}{|l|}{ Functionality } \\
\hline Understandable mechanics & 0 & 1 & 9 & 120 & 3.9154 \\
\hline Responsiveness of the game & 0 & 3 & 11 & 116 & 3.8692 \\
\hline User friendliness & 0 & 3 & 10 & 117 & 3.8769 \\
\hline \multicolumn{6}{|l|}{ Reliability } \\
\hline \multicolumn{6}{|l|}{ Feasibility } \\
\hline Educational tool to the students & 0 & 1 & 7 & 122 & 3.9308 \\
\hline Interactivity of the game to the players & 1 & 4 & 5 & 120 & 3.8769 \\
\hline \multicolumn{6}{|l|}{ Security } \\
\hline Structural design, audio, and visual appearance of the project & 0 & 1 & 10 & 119 & 3.9077 \\
\hline Degree of compactness & 0 & 2 & 12 & 116 & 3.8769 \\
\hline
\end{tabular}


Under the feasibility category, the item of acceptability of the game to be useful as an educational tool to the students has the highest mean of 3.9308 and is marked as "Outstanding" based on Table 1. This means that the respondents found that WISE Game helped them recall or review the lessons they are studying, and the proponents believe that the game can serve as an educational tool for reviewing their lessons and an activity that can interact with others as well, as 122 out of 130 or $93.8 \%$ of the respondents gave the highest score "Excellent" to the item.

The clarity of the game mechanics, the conformance to the desired results, the responsiveness, and the user-friendliness of the game, all under the functionality category, have also received "Outstanding" results. The proponents believed that in terms of the game mechanics, the simplicity and being explained well will help the students to pick up immediately. The aesthetics is also acceptable to the respondents as presented in the results. The degree of compactness was rated "outstanding" by the respondents, as well as the structural design, audio, and visual appearance of the project.

Overall, the ratings for each item goes above 3.26 in terms of mean, which means the results for each item were "Outstanding", based on Table 1. Thus, the overall percentages proved that students from grade 5 to grade 8 are favored in WISE Game. Since the feasibility has the highest percentage, thus, the WISE game is agreed to be effective as an educational tool, being interactive of the game to the players, and its design and mechanics are clear and well explained.

\section{CONCLUSION}

The wireless interactive software educational game can be used as an educational tool that serves as a review material as well as an interactive game that utilizes critical thinking, strategies, and teamwork. Series of tests in every transaction were conducted to test its functionality and reliability. The functionality and reliability of the project is acceptable based on the perspective of 130 different users. Therefore, the proponents considered this project to be convenient, functional, and reliable to use. Future developments can be done in these areas: 1) development of a graphical user interface (GUI) for teachers to access databases for updating questions of the game using JavaScript, PHP, and other programming tools to enable adding and editing of questions encoded to database, 2) Addition of other courses into the database. Additional categories and professional courses can be added with new game mechanics, and 3) Creating a purely digital version of the game through mobile application for different mobile platforms.

\section{REFERENCES}

[1] V. J. Rideout, U. G. Foehr, and D. F. Roberts, "Generation M2: Media in the lives of eight to 18 years old," California: Henry J. Kaiser Family Foundation, 2010.

[2] S. F. Ng, N. S. I. C. Hassan, N. H. M. Nor, and N. A. A. Malek, "The Relationship between Smartphone Use and Academic Performance: A Case of Students in A Malaysian Tertiary Institution," Malaysian Online Journal of Educational Technology, vol. 5, no. 4, pp. 58-70, 2017.

[3] P. Valkenburg and J. Piotrowski, "Plugged In: How Media Attract and Affect Youth," New Haven: Yale University Press, 2017, doi: 10.12987/yale/9780300218879.001.0001.

[4] M. Bickham, F. Bradburn, R. Edwards, J. Fallon, J. Luke, D. Mossman, and L. Van Ness, "Learning in the 21st Century: Teaching Today's Students on Their Terms," The International Education Advisory Board (IEAB), 2008.

[5] B. Kvavik, "Convenience, Communications, and Control: How Students Use Technology," EDUCAUSE Center for Analysis and Research and University of Minnesota, Twin Cities, 2005.

[6] K. L. McClarty, A. Orr, P. M. Frey, R. P. Dolan, V. Vassileva, and A. McVay, "A Literature Review of Gaming in Education," Gaming in education, pp. 1-35, 2012.

[7] B. Sutton, "The Effects of Technology in Society and Education," M.S. thesis, Department of Education and Human Development of the State, University of New York College at Brockport, New York, 2013.

[8] S. Ghavifekr and W. A. W. Rosdy, "Teaching and learning with technology: Effectiveness of ICT integration in schools," International Journal of Research in Education and Science, vol. 1, no. 2, pp. 175-191, 2015, doi: 10.21890/ijres.23596.

[9] C. Venera-Mihaela and I. Boghian, "Teaching the Relevance of Game-Based Learning to Preschool and Primary Teachers," Procedia-Social and Behavioral Sciences, vol. 142, pp. 640-646, 2014, doi: 10.1016/j.sbspro.2014.07.679.

[10] M. Prensky, "Digital Game-Based Learning," New York: M cGraw-Hill, 2001.

[11] A. Burke, "Teacher as leader in a "flat world": Preparing students in a global community," Language Arts Journal of Michigan, vol. 25, no. 2, pp. 13-17, 2010, doi: 10.9707/2168-149X.1071.

[12] P. D. Bruyckere, P. A. Kirschner, and C. D. Hulshof, "Technology in Education: What Teachers Should Know," American Educator, vol. 40, no. 1, pp.12-18, 2016.

[13] C. Lemke, “enGauge 21st Century Skills: Digital Literacies for a Digital Age," Learning in the Digital Age, 2002. 
[14] A. Protopsaltis, S. Hetzner, S. Borotis, T. Connolly, and T. Hainey, "How to Teach Entrepreneurship Using Serious Games and Web 2.0," 2014 IEEE 14th International Conference on Advanced Learning Technologies, 2014, pp. 227-229, doi: 10.1109/ICALT.2014.72.

[15] S-T. Yong and P. Gates, "Born Digital: Are they really digital natives?," International Journal of e-Education, eBusiness, e-Management and e-Learning, vol. 4, no. 2, pp.102-105, 2014, doi: 10.7763/IJEEEE.2014.V4.311.

[16] M. McMahon and R. Pospisil, "Laptops for a digital lifestyle: Millennial students and wireless mobile technologies," Proceedings of the Australasian Society for Computers in Learning in Tertiary Education, 2005, pp. 421-431.

[17] R.L Gerwin., K. Kaliebe, and M. Daigle, "The interplay between digital media use and development," Child and Adolescent Psychiatric Clinics, vol. 27, no. 2, pp.345-355, 2018, doi: 10.1016/j.chc.2017.11.002.

[18] V. Rideout and M. Robb, "The Common Sense Census: Media use by tweens and teens," San Fransisco: Common Sense Media, 2019, doi: 10.1080/17482798.2016.1129808.

[19] J. M. Twenge, G. N. Martin, and B. H. Spitzberg, "Trends in US Adolescents' media use, 1976-2016: The rise of digital media, the decline of TV, and the (near) demise of print," Psychology of Popular Media Culture, vol. 8, no. 4, pp. 329-345, 2019, doi: 10.1037/ppm0000203.

[20] M. Versvik, J. Brooker, and A. Furuseth, Kahoot!, 2015. [Online]. Availale: https://kahoot.com/company/

[21] S. A. Licorish, H. E. Owen, B. Daniel, and J. L. George, "Students' perception of Kahoot!'s influence on teaching and learning," Research and Practice in Technology Enhanced Learning, vol. 13, no. 9, pp. 1-23, 2018, doi: 10.1186/s41039-018-0078-8.

[22] A. I. Wang and R. Tahir, "The effect of using Kahoot! for learning-A literature review," Computers \& Education, vol. 149, art. no. 103818, May 2020, doi: 10.1016/j.compedu.2020.103818.

[23] H. Bicen and S. Kocakoyun, "Perceptions of students for gamification approach: Kahoot as a case study," International Journal of Emerging Technologies in Learning (iJET), vol. 13, no. 02, pp.72-93, 2018, doi: 10.3991/ijet.v13i02.7467.

[24] C. M. Plump and J. LaRosa, "Using Kahoot! in the classroom to create engagement and active learning: A gamebased technology solution for eLearning novices," Management Teaching Review, vol. 2, no. 2, pp.151-158, 2017, doi: $10.1177 / 2379298116689783$

[25] S. de Freitas and T. Neumann, "The use of 'exploratory learning' for supporting immersive learning in virtual environments," Computers and Education, vol. 52, no. 2, pp. 343-352, 2009, doi: 10.1016/j.compedu.2008.09.010.

[26] K. Squire and H. Jenkins, "Harnessing the power of games in education," Insight, vol. 3, pp. 5-33, 2003.

[27] S. de Freitas, "Using games and simulations for supporting learning," Learning, Media and Technology, vol. 31, no. 4, pp. 343-358, 2006, doi: 10.1080/17439880601021967.

[28] R. B. Bloom, "Apache Server 2.0: The Complete Reference,” New York: McGraw-Hill, 2002.

[29] P. DuBois, "MySQL. Addison-Wesley Professional," 5th ed. Boston, Massachusetts: Addison-Wesley, 2013.

[30] R. W. Sudibyo, N. Funabiki and W. Kao, "A Proposal of Hardware Channel Bonding for IEEE802.11N Wireless Network Using Raspberry PI," 2018 IEEE International Conference on Consumer Electronics-Taiwan (ICCE-TW), 2018, pp. 1-2, doi: 10.1109/ICCE-China.2018.8448498.

\section{BIOGRAPHIES OF AUTHORS}

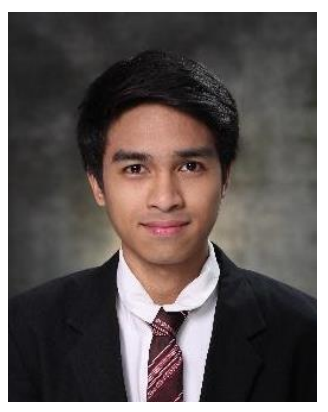

Muel Fred L. Ruiz is a graduate of Bachelor of Science in Electronics Engineering in Technological University of the Philippines Taguig, Philippines. Currently, he is pursuing Master of Science in Engineering with specialization in Electronics Engineering in Polytechnic University of the Philippines Graduate School, City of Manila, Philippines. E-mail: muelfredruiz@gmail.com

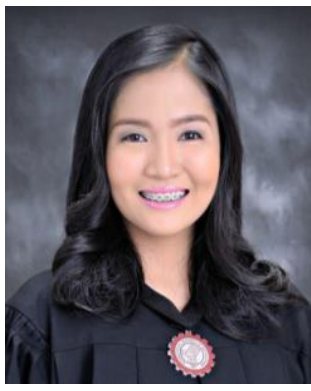

Rica I. Esclada is a graduate of Electronics Engineering Technology and Bachelor of Science in Electronics and Communications Engineering at the Technological University of the Philippines - Taguig. She is currently a Software Engineer specialized in Testing and Quality Assurance at Accenture Inc. specifically in Technology for Operations projects. E-mail: ricaesclada@gmail.com 

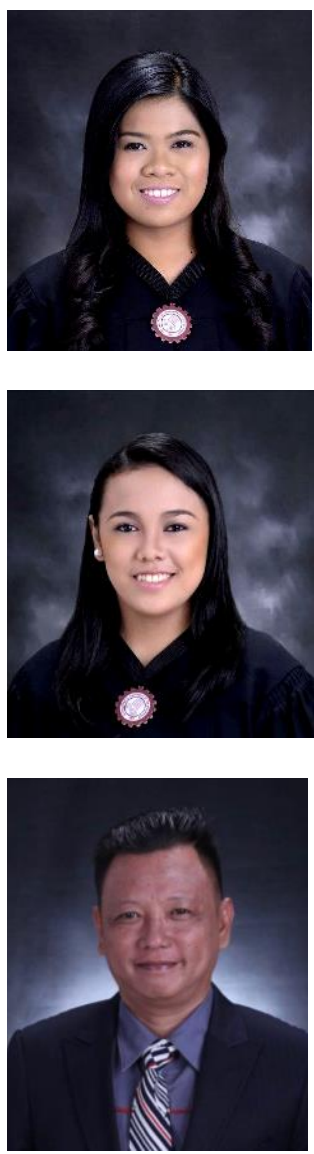

Jannica H. Balderama is a graduate of Electronics Engineering Technology and Bachelor of Science in Electronics and Communications Engineering at the Technological University of the Philippines-Taguig. She is currently a Technical Support Engineer at Sunpower Corporation. E-mail: balderamajannica44@gmail.com

Anzel Anne I. Aguirre is a graduate of Electronics Engineering Technology and Bachelor of Science in Electronics Engineering at the Technological University of the Philippines-Taguig Campus Philippines. She is currently Radio Frequency Engineer at Globe Telecom (FINSI). E-mail: anzelaguirre@gmail.com

Raymund M. Lozada is a graduate of Bachelor of Science in Electronics and Communications Engineering at the University of the East in Manila Philippines. He is also a graduate of Master of Technology Management in University of the Philippines Diliman, Quezon City Philippines. He is currently the Department Head of the Electrical and Allied Department of the Technological University of the Philippines Taguig. Under his Department are Electrical Engineering, Electronics Engineering, Bachelor of Science in Information Technology, Bachelor of Technology Major-in Electrical Technology and Bachelor of Technology-Major in Electronics Technology. E-mail: raymund_lozada@ tup.edu.ph 